\title{
Outcomes in infants $<29$ weeks of gestation following single-dose prophylactic indomethacin
}

\author{
Maria Gillam-Krakauer (1) ${ }^{1} \cdot$ James C. Slaughter ${ }^{2} \cdot$ Robert B. Cotton $^{1} \cdot$ Blaine E. Robinson $^{3} \cdot$ Jeff Reese $^{1,4} \cdot$ \\ Nathalie L. Maitre $\mathbb{B}^{5,6}$
}

Received: 1 March 2020 / Revised: 5 August 2020 / Accepted: 2 September 2020 / Published online: 18 September 2020

(c) The Author(s), under exclusive licence to Springer Nature America, Inc. 2020

\begin{abstract}
Background Prophylactic indomethacin (3 doses) decreases patent ductus arteriosus (PDA) and intraventricular hemorrhage (IVH) in preterm infants. The study aim was to determine whether single-dose indomethacin (SD-INDO) decreases PDA, IVH, and improves motor function.

Methods A retrospective cohort (2007-2014) compared infants born $<29$ weeks who did $(n=299)$ or did not $(n=85)$ receive SD-INDO and estimated outcomes association with ordinal logistic regression, adjusting for multiple variables using propensity scores.

Results Infants who received SD-INDO were more premature $(p<0.001)$ but had lower odds of PDA (OR 0.26 [0.15, 0.44], $p<0.005)$, PDA receiving treatment (OR 0.12 [0.03, 0.47], $p<0.005)$, death $(\mathrm{OR} 0.41[0.20,0.86], p=0.02)$, and CP severity (OR 0.33 [0.12, 0.89], $p=0.03$ ). There was less IVH (OR 0.58 [0.36, 0.94], $p=0.03$ ) when adjusted for gestational age.

Conclusions SD-INDO is associated with decreased PDA and CP severity and improved survival.
\end{abstract}

\section{Introduction}

Despite advances in the field of neonatology, infants born very prematurely remain at risk for patent ductus arteriosus

These authors contributed equally: Jeff Reese and Nathalie L. Maitre

Supplementary information The online version of this article (https:// doi.org/10.1038/s41372-020-00814-9) contains supplementary material, which is available to authorized users.

Maria Gillam-Krakauer

Maria.Krakauer@vumc.org

1 Mildred T. Stahlman Division of Neonatology, Department of Pediatrics, Vanderbilt University Medical Center, Nashville, TN, USA

2 Department of Biostatistics, Vanderbilt University Medical Center, Nashville, TN, USA

3 Vanderbilt University Medical Center, Nashville, TN, USA

4 Department of Cell and Developmental Biology, Vanderbilt University Medical Center, Nashville, TN, USA

5 Department of Pediatrics Nationwide Children's Hospital, Columbus, OH, USA

6 Department of Hearing and Speech Sciences, Vanderbilt University Medical Center, Nashville, TN, USA
(PDA), intraventricular hemorrhage (IVH), chronic lung disease and other complications. The incidence of a hemodynamically significant PDA (hsPDA) is as high as $70 \%$ in infants born at 23-24 weeks and 59\% in those born at 25-28 weeks [1]. Spontaneous closure of a hsPDA is rare in the most premature infants $(19 \%)$ and there is a high incidence of failure to respond to pharmacologic intervention (69\% at 23-24 weeks, compared with $40 \%$ at 25-28 weeks) [1-6]. Infants born extremely prematurely are also at high risk for IVH. Indomethacin is one of the few postnatal interventions shown to decrease IVH. Intravenous indomethacin administered "prophylactically" in three to six doses beginning at $6-12 \mathrm{~h}$ of age reduces the incidence of hsPDA [3, 7-9] and decreases IVH [3, 9-12] in addition to decreasing pulmonary hemorrhage [11], vasopressordependent hypotension [13], and chronic lung disease [7, 14]. Prophylactic indomethacin has also been associated with decrease in mortality and may play an important role in the current era where babies born as young as 22 weeks of gestation are surviving [14]. A recent study by Bhat et al. found a single dose of indomethacin to be as effective as a three dose regimen in preventing all grades of IVH and white matter injury [15].

Prophylactic indomethacin decreases the risk of intraventricular hemorrhage (IVH) $[3,9,10,12,16-18]$. 
Severe IVH is a major antecedent of cerebral palsy (CP), which affects $19 \%$ of extremely low birth weight (EBLW) infants (birth weight $<1000 \mathrm{~g}$ ) $[19,20]$. Although multiple studies show a decrease in severe (grade 3 and 4) IVH with early indomethacin, the evidence to support longterm benefits of prophylactic indomethacin has been less compelling [3, 21]. Reliance on head ultrasound results and presence of $\mathrm{CP}$ as long-term neurologic measures may underestimate the prevalence of motor disability in this population, since $9 \%$ of extremely low birth weight (ELBW) infants develop CP despite normal head ultrasound [19] and, in preterm infants without $\mathrm{CP}$, the prevalence of mild-moderate and moderate motor impairment is $40.5 / 100$ and $19.0 / 100$, respectively [22]. Although motor delays and impairments in the absence of cerebral palsy impact later adaptive function, they have not been the focus of prophylactic indomethacin studies.

We previously showed that a single dose of indomethacin (SD-INDO) given at $24 \mathrm{~h}$ prevents symptomatic PDA and minimizes drug exposure [23], thus, our center has followed an SD-INDO protocol since 1987. Although the original trial studied a single dose given at $24 \mathrm{~h}$ of age, following that study our center implemented a protocol to give indomethacin at $12 \mathrm{~h}$ with the intent to provide benefit on the day of birth when factors are present which increase the risk of intraventricular bleeding. That study was performed prior to widespread use of antenatal corticosteroids and exogenous surfactant in a cohort of preterm patients with an average gestational age of 29 weeks. Our center has not re-examined the effect of an SD-INDO protocol in the modern era of neonatology. Although most qualifying infants at our center receive SD-INDO, during the study period there were a number of patients who did not receive the intervention due to drug shortage, medical provider preference, or other cause (Appendix A and Supplementary Table 1), creating a contemporaneous convenience sample group for comparison.

The goal of the present study was to evaluate short-term morbidities and determine the longer-term motor outcomes of SD-INDO in the current era of management of very premature infants. We hypothesized that exposure to SDINDO would be associated with decreased risk of (1) developing hsPDA, (2) receiving pharmacologic treatment for PDA, or (3) developing more severe intraventricular hemorrhage. We also hypothesized that SD-INDO would be associated with improved motor outcomes at 24-36 months of age. To test our hypotheses, we conducted a retrospective study of all premature infants born $<29$ weeks' gestation at our institution over a seven-year period and compared outcomes between infants who received SD-INDO and those who did not.

\section{Materials and methods}

\section{Study population}

This was a retrospective cohort study of all eligible patients admitted to the neonatal intensive care unit (NICU) (01/ 2007-03/2014) using data entered prospectively into our internal NICU computerized database and the electronic medical record (EMR). The years 2007-2014 were selected since no major changes in other clinical protocols existed to confound results and allowed for three-year developmental follow-up. There was an equal distribution of treated and non-treated patients over this period. Based on a fixed sample size of 384 subjects with $80 \%$ of subjects receiving SD-INDO, we determined $80 \%$ power to detect an odds ratio of 0.45 (or 2.2) when considering binary outcomes. Actual power will be higher because outcomes are modeled more efficiently using ordinal rather than binary regression models. Approval was obtained from the Vanderbilt University Medical Center (VUMC) Institutional Review Board and informed consent waived due to the retrospective study design.

Infants born at $<29$ weeks' gestation who survived to at least $12 \mathrm{~h}$ of age were included. Although our NICU indomethacin protocol included patients born $<32$ weeks' gestation, excluding the more mature infants for this study allowed us to focus on the population, based on gestational age, most at risk for hsPDA. Outborn infants were included if they arrived at the NICU within $12 \mathrm{~h}$ of birth. Infants were excluded if major contraindications to the SD-INDO protocol existed (disseminated intravascular coagulopathy, congenital malformations such as congenital heart disease) or they exhibited gastrointestinal malformations or recognized genetic syndromes. Eligible patients were identified using a computerized internal database of all patients admitted to the NICU and pertinent data (medication orders, medication administration record, illness severity score variables and renal function, radiology and echocardiography records, and NICU follow-up testing) was manually extracted from the database, confirmed in the electronic medical record (EMR) by up to 4 investigators, and entered into a REDCap database (UL1 TR000445 from NCATS/NIH).

Infants were classified into exposed and non-exposed groups based on receipt of SD-INDO, a single dose of indomethacin $0.2 \mathrm{mg} / \mathrm{kg}$ at $12 \mathrm{~h}$ of age (Appendix A). Reasons for non-exposure included suspected but later disproven pathologies, conditions which placed the infant at higher risk for spontaneous intestinal perforation, conditions that increased risk of bleeding, low urine output, or reassuring clinical status/provider preference/drug shortage (Supplementary Table 1). 
A patent ductus arteriosus was deemed hemodynamically significant (hsPDA) if pediatric cardiologists considered the ductus vessel size to be medium or large by color Doppler with left-to-right flow and additional echo criteria were met (as noted below) AND the infant had clinical signs consistent with excessive left-to-right flow through the vessel (which could not be reasonably be attributed to other causes): murmur, tachypnea, tachycardia, bounding pulses, pulmonary edema, increasing oxygen requirement, increasing requirement for positive end-expiratory pressure (PEEP), decreasing urine output, or renal failure. In addition to a protocol for prophylactic treatment with indomethacin, our unit has standard criteria for treating a PDA with indomethacin: a clinically symptomatic hsPDA not responsive to medical management meeting commonly-used echocardiogram criteria (left-to-right shunting at the ductus arteriosus AND increased left atrial (LA) or left ventricular size (LA/aorta (AO) ratio $>1.5$ ), OR retrograde diastolic aortic flow at the level of the diaphragm) (Appendix B). Medical management, using fluid restriction (targeted intake of $120 \mathrm{ml} / \mathrm{kg} / \mathrm{d}$ ) and increased PEEP, was attempted prior to using pharmacologic treatment.

Surgical ligation of a PDA was performed for infants who had renal failure or intestinal pathology precluding the use of indomethacin, or for those with a persistent hsPDA despite two courses of indomethacin with evidence of cardiac strain or requiring increasing ventilator support.

Per unit protocol, all neonates were evaluated for evidence of neural insults on cranial ultrasound at least twice, at seven and 30 days of age. Using the grading system of Papile et al. [24], the most severe head ultrasound result for each neonate was recorded. Data on surgical ligation of the ductus arteriosus, spontaneous intestinal perforation (defined as a focal small bowel perforation without pneumatosis with pathology confirmation, when available; SIP) [25], necrotizing enterocolitis at Bell's Stage II or above (NEC) [26], retinopathy of prematurity requiring laser surgery (ROP), postnatal steroids, days on ventilator, discharge to home on oxygen, length of stay, and death were obtained from the medical record. Renal function (urine output and serum creatinine concentration at 12, 24 and 72 h) were obtained from the EMR and the presence of acute kidney injury (AKI) was assessed at 24 and $72 \mathrm{~h}$ using the neonatal-modified AKI Kidney Disease: Improving Global Outcomes (KDIGO) classification scheme [27]. Illness severity was measured using the CRIB II [28] and SNAPPE-II [29] scores.

Trained examiners evaluated motor performance at 12 months of age using the Developmental Assessment of Young Children (DAYC) and at 24-36 months of age using the Bayley Scales of Infant and Toddler Development, 3rd Edition (Bayley) [30]. The 36-month score was used unless they were lost to follow-up after the 24-month score, in which case the 24-month score was used. The scores were adjusted for gestational age and thus represent postconceptual age. Presence and severity of CP was evaluated using standard neurologic algorithms for preterm infants [31]. CP was classified by developmental specialists according to the Gross Motor Function Classification System (GMFCS) [4, 6, 32].

\section{Statistical analysis}

Demographic characteristics were compared between groups using the Wilcoxon rank sum test for continuous variables and Pearson's chi-squared test for categorical variables. To estimate associations with exposure to SDINDO, we used separate proportional odds regression models for each outcome [33]. The proportional odds model generalizes the Wilcoxon rank sum test to a multivariable model to adjust for confounders and reduces to the usual logistic regression model if the outcome is binary. For each outcome, we fit unadjusted (SD-INDO only), minimally adjusted (SD-INDO and GA), and propensity score-adjusted models (SD-INDO and propensity score). Propensity scores were estimated using a multivariable logistic regression model where GA, sex, inborn status (transport), mode of delivery [34, 35], and ethnicity [36] were used to predict the probability of receiving SD-INDO [37]. Variables selected for the propensity score were ones for which evidence suggested association with outcomes and could have influenced ordering providers. We compared distribution of propensity scores by SD-INDO status and found significant overlap, so all subjects were included in the analysis. Estimated propensity scores were then included in the multivariable models to mitigate residual confounding. Estimates from the propensity score-adjusted models were compared to the GA adjusted models to ascertain if the odds ratio estimate changed by a scientifically relevant amount. All analyses were conducted using $\mathrm{R}$ statistical software (version 3.1.2) following guidelines for reproducible research [38].

\section{Results}

We identified 384 infants who met criteria to receive SDINDO per the established protocol. Of these, $299(77.9 \%)$ received SD-INDO and $85(22.1 \%)$ did not (Fig. 1 and Supplementary Table 1). Infants who received SD-INDO were more immature at birth (median gestational age 26 vs. 27 weeks, $p<0.001)$ and more likely to be inborn (72 vs. $56 \%, p=0.008$ ) with statistically lower Apgar and higher CRIB-II scores (Tables 1 and 2). There was no significant difference in the incidence of birthweight $<3 \%$ tile between the two groups. 


\section{Renal and hemodynamic outcomes (Table 2)}

SD-INDO was not associated with acute kidney injury or lower urine output. Despite a statistically significant higher serum creatinine concentration at $72 \mathrm{~h}$, infants who received SD-INDO had a lower KDIGO score at $24 \mathrm{~h}$ and no difference in KDIGO score at $72 \mathrm{~h}$. Although infants exposed to SD-INDO had marginally lower mean blood pressures at $12 \mathrm{~h}$ of age, there was no difference in use of glucocorticoids for hypotension in the first 3 days between the two groups $(18 \%$ vs $23 \%, p=0.31)$.

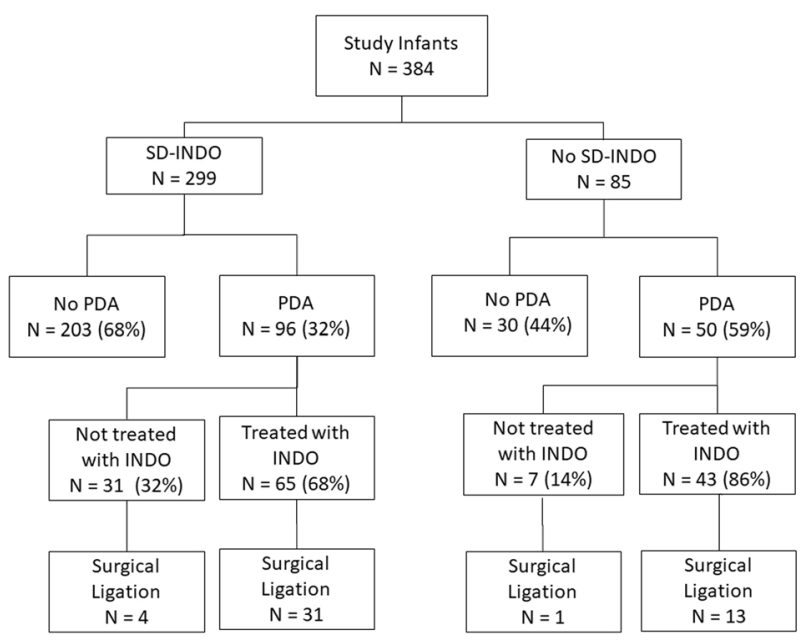

Fig. 1 Study flow diagram. INDO Indomethacin for treatment of a hemodynamically significant patent ductus arteriosus, PDA patent ductus arteriosus, SD-INDO single-dose indomethacin for prophylaxis.

\section{Short-term outcomes (Table 3)}

SD-INDO exposure was associated with lower propensity score-adjusted odds of developing hsPDA (OR 0.26, $95 \%$ CI $[0.15,0.44], p<0.005)$ and lower odds of receiving treatment for hsPDA with indomethacin (OR $0.12,95 \%$ CI $[0.03,0.47], p<0.005)$, but was not associated with reduced incidence of surgical ligation. Infants exposed to SD-INDO at $12 \mathrm{~h}$ had lower gestational-age adjusted odds of higher grade IVH (OR $0.58,95 \%$ CI $[0.36,0.94], p=0.03$ ) but there was no statistically significant difference in odds of higher grade IVH between the two groups with propensity score adjustment. There was no difference in the incidence of cerebellar hemorrhage (OR $0.41,95 \%$ CI $[0.13,1.26], p=0.12)$, SIP, or NEC between groups and no infants in our cohort experienced coagulopathy or clinical hemorrhage attributable to SD-INDO.

\section{Long term outcomes (Table 4)}

There were 334 patients (87\%) who survived to discharge. SD-INDO was associated with decreased odds of death before discharge (OR $0.41,95 \%$ CI [0.20, 0.86], $p=0.02$ ), CP (OR $0.35,95 \%$ CI [0.13, 0.95], $p=0.04)$ and death or GMFCS $>3$ (OR 0.32, 95\% CI [0.16, 0.64], $p<0.005$ ). DAYC testing was performed in 286 ( $86 \%$ of survivors) and Bayley testing was performed in 190 (57\% of survivors). There was no significant difference in motor scores on the DAYC or Bayley between surviving infants who received SD-INDO and those who did not. Of the infants who developed CP, those who received SD-INDO had
Table 1 Demographics of SDINDO treated infants vs. untreated.

\begin{tabular}{lccc}
\hline & $\begin{array}{l}\text { SD-INDO } \\
n=299\end{array}$ & $\begin{array}{l}\text { No SD-INDO } \\
n=85\end{array}$ & $p$ \\
\hline EGA in weeks, median (IQR) & $26(25,27)$ & $27(26,28)$ & $<0.001^{\mathrm{b}}$ \\
Birth Weight, median (IQR) & $810(698,920)$ & $905(730,1050)$ & $<0.001^{\mathrm{b}}$ \\
Weight $<3 \%, n(\%)$ & $14(5)$ & $5(6)$ & $0.65^{\mathrm{a}}$ \\
Apgar 1 min, median (IQR) & $4(1,6)$ & $5(2,7)$ & $0.002^{\mathrm{b}}$ \\
Apgar 5 min, median (IQR) & $6(5,7)$ & $7(6,8)$ & $0.007^{\mathrm{b}}$ \\
CRIB II, median (IQR) & $11(9,13)$ & $9(8,12)$ & $0.014^{\mathrm{b}}$ \\
SNAPPE II, median (IQR) & $33(20,47)$ & $62(73)$ & $0.67^{\mathrm{b}}$ \\
Antenatal steroids, $n(\%)$ & $232(78)$ & $57(67)$ & $0.34^{\mathrm{a}}$ \\
Delivery by cesarean, $n(\%)$ & $219(73)$ & $42(49)$ & $0.38^{\mathrm{a}}$ \\
Female, $n(\%)$ & $154(52)$ & $48(56)$ & $0.73^{\mathrm{a}}$ \\
Inborn, $n(\%)$ & $214(72)$ & & $0.008^{\mathrm{a}}$ \\
Ethnicity, $n(\%)$ & $129(43)$ & $32(38)$ & $0.63^{\mathrm{a}}$ \\
Asian, Black or Hispanic & $170(57)$ & $53(62)$ & \\
Caucasian & &
\end{tabular}

$p$ determined by using ${ }^{\mathrm{a} P e a r s o n} \chi^{2}$ test; ${ }^{\mathrm{b}}$ Wilcoxon test.

$S D$-INDO Single-Dose Indomethacin, EGA estimated gestational age, IQR interquartile range (25th, 75th). 
Table 2 Renal and hemodynamic outcomes in SD-INDO treated infants vs. untreated.

\begin{tabular}{|c|c|c|c|}
\hline & $\begin{array}{l}\text { SD-INDO } \\
n=299\end{array}$ & $\begin{array}{l}\text { No SD-INDO } \\
n=85\end{array}$ & $p$ \\
\hline \multicolumn{4}{|c|}{ Urine output $(\mathrm{ml} / \mathrm{kg} / \mathrm{h})$, median (IQR) } \\
\hline $12 \mathrm{~h}$ & $\begin{array}{l}1.90 \\
(1.03,2.94)\end{array}$ & $\begin{array}{l}1.77 \\
(0.62,2.46)\end{array}$ & $0.077^{\mathrm{a}}$ \\
\hline $24 \mathrm{~h}$ & $2.5(1.9,3.2)$ & $2.6(1.8,3.4)$ & $1^{\mathrm{a}}$ \\
\hline $72 \mathrm{~h}$ & $3.5(2.6,4.2)$ & $3.5(2.4,4.2)$ & $0.72^{\mathrm{a}}$ \\
\hline \multicolumn{4}{|c|}{ Creatinine (mg/dL), median (IQR) } \\
\hline $12 \mathrm{~h}$ & $\begin{array}{l}0.82 \\
(0.72,0.94)\end{array}$ & $\begin{array}{l}0.83 \\
(0.75,0.97)\end{array}$ & $0.66^{\mathrm{a}}$ \\
\hline $24 \mathrm{~h}$ & $\begin{array}{l}0.97 \\
(0.83,1.09)\end{array}$ & $\begin{array}{l}0.90 \\
(0.82,1.04)\end{array}$ & $0.14^{\mathrm{a}}$ \\
\hline $72 \mathrm{~h}$ & $\begin{array}{l}1.01 \\
(0.86,1.18)\end{array}$ & $\begin{array}{l}0.92 \\
(0.83,1.10)\end{array}$ & $0.028^{\mathrm{a}}$ \\
\hline $\begin{array}{l}\text { KDIGO score } 24 \mathrm{~h}, \\
n(\%)\end{array}$ & & & $0.014^{\mathrm{b}}$ \\
\hline 0 & $221(74)$ & $48(58)$ & \\
\hline 1 & $72(24)$ & $31(37)$ & \\
\hline 2 & $6(2)$ & $4(5)$ & \\
\hline $\begin{array}{l}\text { KDIGO score } 72 \mathrm{~h}, \\
n(\%)\end{array}$ & & & $0.71^{\mathrm{b}}$ \\
\hline 0 & $237(82)$ & $66(85)$ & \\
\hline 1 & $50(17)$ & $11(14)$ & \\
\hline 2 & $2(1)$ & $1(1)$ & \\
\hline $\begin{array}{l}\text { Mean } \mathrm{BP} \text { at } 12 \mathrm{~h} \text {, } \\
\text { median (IQR) }\end{array}$ & $32(29,36)$ & $35(30,38)$ & $0.027^{\mathrm{a}}$ \\
\hline $\begin{array}{l}\text { Hydrocortisone at }<72 \mathrm{~h} \\
\text { of age }\end{array}$ & $53(18)$ & $19(23)$ & $0.31^{\mathrm{b}}$ \\
\hline
\end{tabular}

$p$ determined by using ${ }^{\mathrm{a}}$ Wilcoxon test; ${ }^{\mathrm{b}}$ Pearson test.

$S D$-INDO Single-Dose Indomethacin, KDIGO Neonatal Acute Kidney Injury Classification [64], $B P$ Blood pressure, $I Q R$ interquartile range (25th, 75th)

better functional outcomes using the GMFCS (OR 0.14, $95 \%$ CI [0.02, 0.99], $p=0.05)$.

\section{Discussion}

This study examined the cardiovascular and neurodevelopmental outcomes of a single-dose indomethacin protocol for premature infants who are at high risk for PDA, IVH, and neurodevelopmental delays. Our results suggest that infants born $<29$ weeks who receive SD-INDO, when compared to infants who do not, experience a lower incidence of PDA and improved survival without increasing the incidence of IVH or AKI. There is also an association with decreased functional impairment when $\mathrm{CP}$ is present.

The effectiveness of a single dose of indomethacin given prophylactically, as opposed to a longer course, is likely due to the reduced elimination rate of indomethacin in the immediate period after birth. Clearance of indomethacin is inversely related to gestational maturity and linearly correlated with postnatal age, resulting in a longer half-life during the first few days after birth, particularly in the smallest preterm infants [3, 9, 10, 12, 16-18, 39-44]. Yaffe et al. showed that significantly higher serum indomethacin concentrations were achieved in neonates to whom $0.2 \mathrm{mg} /$ $\mathrm{kg}$ of indomethacin was administered at $<2$ days of age compared to those who were 2-7 days or $>7$ days of age and in babies whose body weight was $<1000 \mathrm{~g}$ compared to those $>1000 \mathrm{~g}$ [40]. A single-dose regimen may therefore result in similar outcomes to those produced by longer regimens $[3,9,18-20]$, while decreasing drug exposure.

We found a significant association between exposure to SD-INDO and decreased IVH in the gestation-adjusted, but not the propensity-adjusted model. The SD-INDO group was gestationally more preterm and had lower Apgar scores and higher CRIB II scores, which suggests that they were sicker at baseline. It is possible that selection bias exists in our cohort due to the retrospective nature of the study. However, our findings are consistent with previous studies which show that a 3-dose regimen of prophylactic indomethacin decreases grade $2-4[9,16,22]$ and 3-4 IVH $[3,16,23]$ without adverse neurologic consequences $[10,24]$. Our results are also consistent with findings by Bhat et al., using a non-inferiority analysis, who found no difference in IVH and cerebellar hemorrhage rates between patients who received a 1-dose versus a 3-dose regimen of prophylactic indomethacin. In contrast to their study, we compared non-treated infants to those who received prophylaxis. Because our study compared patients who received SD-INDO to those who did not, we were also able to note a potential survival benefit associated with SD-INDO.

One strength of our study is that we followed long-term neurodevelopmental outcomes. Despite a clear connection between prophylactic indomethacin and decreased IVH, only one study has shown an improvement in long-term outcomes [45]. The lack of improvement in other long-term outcome studies may be due to lack of association with the specific outcomes measured (CP, death, blindness or deafness) [3] or lack of statistical power for the rare outcomes measured [6]. Alternatively, the early benefits of indomethacin prophylaxis may be dampened by neuroplasticity and environmental compensation over time, as noted for some caffeine-associated long-term neurodevelopmental benefits [46]. Cerebral palsy, typically measured as a binary outcome, may underestimate meaningful motor disability not meeting criteria for CP. We used Bayley fine and gross motor scores to evaluate for dysfunction in the motor tracts, which are affected by IVH. Previous prophylactic indomethacin studies did not investigate the continuum of motor impairments and delays prevalent in infants born extremely prematurely by school age. Motor delays and impairments 
Table 3 Outcomes at hospital discharge in SD-INDO exposed infants vs. untreated.

\begin{tabular}{|c|c|c|c|c|c|c|c|c|}
\hline \multirow[b]{2}{*}{ Outcome } & \multirow[b]{2}{*}{$\begin{array}{l}\text { SD-INDO \% } \\
(n)\end{array}$} & \multirow[b]{2}{*}{$\begin{array}{l}\text { No SD- } \\
\text { INDO \% (n) }\end{array}$} & \multicolumn{3}{|c|}{ 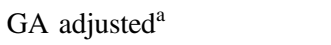 } & \multicolumn{3}{|c|}{ Propensity score adjusted } \\
\hline & & & OR & $95 \% \mathrm{Cl}$ & $p$ & OR & $95 \% \mathrm{Cl}$ & $p$ \\
\hline PDA & $32(96 / 299)$ & $59(50 / 85)$ & 0.24 & {$[0.14,0.41]$} & $<0.005$ & 0.26 & {$[0.15,0.44]$} & $<0.005$ \\
\hline PDA treated ${ }^{\mathrm{c}}$ & $68(65 / 96)$ & $86(43 / 50)$ & 0.10 & {$[0.03,0.40]$} & $<0.005$ & 0.12 & {$[0.03,0.47]$} & $<0.005$ \\
\hline Surgical Ligation $^{\mathrm{c}}$ & $36(35 / 96)$ & $28(14 / 50)$ & 0.98 & {$[0.39,2.46]$} & 0.97 & 1.37 & {$[0.58,3.25]$} & 0.47 \\
\hline IVH & & & 0.58 & {$[0.36,0.94]$} & 0.03 & 0.69 & {$[0.42,1.12]$} & 0.13 \\
\hline No hemorrhage & $62(184 / 299)$ & $55(47 / 85)$ & & & & & & \\
\hline Grade $1 / 2$ & $26(79 / 299)$ & $31(26 / 85)$ & & & & & & \\
\hline Grade $3 / 4$ & $12(36 / 299)$ & $14(12 / 85)$ & & & & & & \\
\hline $\begin{array}{l}\text { Cerebellar } \\
\text { hemorrhage }\end{array}$ & $4(12 / 299)$ & $6(5 / 85)$ & 0.50 & {$[0.16,1.55]$} & 0.23 & 0.41 & {$[0.13,1.26]$} & 0.12 \\
\hline Postnatal steroids ${ }^{\mathrm{d}}$ & $18(53 / 299)$ & $22(19 / 85)$ & 0.56 & {$[0.30,1.05]$} & 0.07 & 0.50 & {$[0.27,0.95]$} & 0.04 \\
\hline SIP & $5(16 / 299)$ & $5(4 / 85)$ & 0.87 & {$[0.28,2.71]$} & 0.81 & 0.97 & {$[0.30,3.09]$} & 0.95 \\
\hline NEC Stage 2-3 & $8(24 / 299)$ & $9(8 / 85)$ & 1.18 & {$[0.56,2.47]$} & 0.67 & 1.12 & {$[0.53,2.38]$} & 0.77 \\
\hline ROP & $4(13 / 299)$ & $2(2 / 85)$ & 1.18 & {$[0.25,5.54]$} & 0.84 & 1.26 & {$[0.27,5.92]$} & 0.77 \\
\hline Death & $12(36 / 299)$ & $16(14 / 85)$ & 0.43 & {$[0.20,0.95]$} & 0.04 & 0.41 & {$[0.20,0.86]$} & 0.02 \\
\hline $\begin{array}{l}\text { Discharge on } \\
\text { Oxygen }^{\mathrm{e}}\end{array}$ & $40(105 / 263)$ & $27(19 / 71)$ & 1.32 & {$[0.71,2.44]$} & 0.38 & 1.26 & {$[0.68,2.34]$} & 0.46 \\
\hline $\begin{array}{l}\text { Ventilator days } \\
\text { (M, IQR) }\end{array}$ & $12(3,32)$ & $9(1,25)$ & 1.45 & {$[0.92,2.28]$} & 0.11 & 1.39 & {$[0.88,2.22]$} & 0.16 \\
\hline $\operatorname{LOS}^{\mathrm{e}}(\mathrm{M}, \mathrm{IQR})$ & $87(64,111)$ & $71(44,108)$ & 1.05 & {$[0.65,1.69]$} & 0.84 & 1.19 & {$[0.73,1.94]$} & 0.49 \\
\hline
\end{tabular}

$S D$-INDO single-dose indomethacin, $P D A$ patent ductus arteriosus diagnosed on echocardiogram, IVH intraventricular hemorrhage, $S I P$ spontaneous intestinal perforation, $N E C$ necrotizing enterocolitis Bell stage $\mathrm{II}^{21}$ or above, ROP retinopathy of prematurity, LOS length of stay, IQR interquartile range (25th, 75th).

${ }^{\text {a }}$ Proportional odds regression.

${ }^{b}$ Propensity score adjustment model includes GA, sex, inborn status (transport), mode of delivery and ethnicity.

${ }^{c}$ Of infants with PDA on echocardiogram ( $n=96$ for SD-INDO group and $n=50$ for No SD-INDO group).

${ }^{\mathrm{d}}$ Postnatal corticosteroids at any time.

${ }^{\mathrm{e}}$ Of survivors to discharge.

may constitute a more suitable outcome to examine the indirect effects of SD-INDO on white matter injury when sample size limitations exist, because they are less influenced by socioeconomic and educational factors during infancy and early childhood [3, 20]. SD-INDO appears to alter the severity of cerebral palsy, with those affected having better functioning as measured by GMFCS if they received SD-INDO, although the numbers of patients with $\mathrm{CP}$ in this study were small.

It is possible that ischemic white matter injury, another important contributor to motor impairment, may confound analysis of the long-term effects of prophylactic indomethacin. The presence of even a mild white matter injury increases the risk of motor impairment fivefold [47]. We did not exclude patients with non-IVH white matter injury from our study, as this has not previously been an exclusion criterion studies of prophylactic indomethacin. On the other hand, Miller et al. found that infants who received 6 , rather than 3 , doses of prophylactic indomethacin had a lower risk of developing moderate to severe white matter injury [48].
Our single-dose protocol may provide a less protective effect for this outcome.

Other strengths of this study are our center's long-term use of a single-dose approach to prophylactic indomethacin, the comparison of SD-INDO to no treatment, which to the best of our knowledge has not been published elsewhere, the length of time over which the present study was performed, and the inclusion of motor score subscales from neurodevelopmental testing and stratification by $\mathrm{CP}$ subtypes. Our study was less likely to overestimate a difference between the SD-INDO exposed and unexposed groups, because the unexposed patients were more mature (and thus less likely to sustain IVH), and the rates of PDA for those infants not treated with SD-INDO are similar to rates reported in the literature for the same gestational age [1].

The limitations of this study include its retrospective nature, precluding the establishment of causal relationships. We did not include patients who died before twelve hours of age, so our study may overestimate survival benefit. On the other hand, the intervention group was approximately 
Table 4 Neurodevelopmental outcomes in SD-INDO treated infants vs. untreated.

\begin{tabular}{|c|c|c|c|c|c|c|c|c|c|}
\hline \multirow[b]{2}{*}{ Outcome } & \multirow[b]{2}{*}{ SD-INDO } & \multirow[b]{2}{*}{ No SD-INDO } & \multirow[b]{2}{*}{$N$} & \multicolumn{3}{|c|}{ GA adjusted } & \multicolumn{3}{|c|}{$\begin{array}{l}\text { Propensity score } \\
\text { adjusted }\end{array}$} \\
\hline & & & & OR & $95 \% \mathrm{CI}$ & $p$ & OR & $95 \% \mathrm{CI}$ & $p$ \\
\hline & Median (IQR) & Median (IQR) & & & & & & & \\
\hline $\begin{array}{l}\text { DAYC Motor } \\
12 \text { months }\end{array}$ & $100(94,106)$ & $102(91,112)$ & 286 & 0.86 & {$[0.50,1.49]$} & 0.59 & 0.80 & {$[0.46,1.38]$} & 0.43 \\
\hline $\begin{array}{l}\text { Bayley Motor } \\
\text { Composite }\end{array}$ & $94(86,100)$ & $94(91,100)$ & 190 & 0.86 & {$[0.46,1.60]$} & 0.64 & 0.87 & {$[0.46,1.64]$} & 0.66 \\
\hline $\begin{array}{l}\text { Bayley } \\
\text { Fine Motor }\end{array}$ & $10(8,11)$ & $9(8,11)$ & 190 & 1. 41 & {$[0.61,2.15]$} & 0.68 & 1.12 & {$[0.59,2.14]$} & 0.74 \\
\hline $\begin{array}{l}\text { Bayley } \\
\text { Gross Motor }\end{array}$ & $8(6.5,9.5)$ & $9(8,10)$ & 190 & 0.66 & {$[0.35,1.25]$} & 0.20 & 0.70 & {$[0.36,1.33]$} & 0.27 \\
\hline $\begin{array}{l}\text { Cerebral Palsy, } \\
n(\%)\end{array}$ & $16(6)$ & $7(12)$ & 309 & 0.39 & {$[0.15,1.04]$} & 0.06 & 0.35 & {$[0.13,0.95]$} & 0.04 \\
\hline $\begin{array}{l}\text { GMFCS > 3, } \\
n(\%)^{\mathrm{a}}\end{array}$ & $1(6)$ & $3(43)$ & 23 & 0.09 & {$[0.01,0.82]$} & 0.03 & 0.14 & {$[0.02,0.99]$} & 0.05 \\
\hline CP type, $n(\%)$ & & & 309 & 0.38 & {$[0.14,1.00]$} & 0.05 & 0.33 & {$[0.12,0.89]$} & 0.03 \\
\hline Hemiplegia & $8(3)$ & $2(3)$ & & & & & & & \\
\hline Diplegia & $6(2)$ & $2(3)$ & & & & & & & \\
\hline Quadriplegia & $2(1)$ & $3(5)$ & & & & & & & \\
\hline
\end{tabular}

$p$ determined by using Pearson $\chi^{2}$ test.

Propensity score adjustment model includes GA, sex, inborn status (transport), mode of delivery, ethnicity, antenatal steroids and small for gestational age $<3 \%$.

$S D$-INDO single-dose indomethacin, DAYC Developmental Assessment of Young Children, GMFCS Gross Motor Function Classification System, IQR interquartile range (25th, 75th).

${ }^{a}$ Of those with cerebral palsy.
1 week younger, which would place them at higher risk for the primary and secondary outcomes and thus potentially underestimate effect. Adherence to the institutional SDINDO protocol was not mandated during the study period, although the contraindications resulting in exclusion from the protocol were strictly observed. The reasons the majority (80\%) of the patients did not receive SD-INDO would not be considered increased risk for neurodevelopmental impairment (low urine output in the first $12 \mathrm{~h}$, suspected but disproven fetal condition, reassuring clinical status, provider preference, drug shortage). Thirteen percent (11/85) of the patients did not receive SD-INDO due to recent maternal tocolysis with indomethacin. Patients in our center are not eligible to receive prophylactic indomethacin if they are exposed to indomethacin in utero for tocolysis within $72 \mathrm{~h}$ of birth due to concern for renal failure from multiple exposures to indomethacin [49]. The number of patients who did not receive SD-INDO due to indomethacin tocolysis was small and the retrospective nature of our study precluded evaluation of the effect on IVH. Significantly more of the non-SD-INDO exposed patients were outborn. Watson et al. found that outborn status, when adjusted for potential confounders, is not significantly associated with IVH [50]. The rates of follow up for Bayley testing were low which could have precluded finding an effect from SD-
INDO, should one exist. We were able to determine presence or absence of CP in a much greater number of patients due to other medical provider visits in the health network (primary care physician, neurology, orthopedics, etc.), even if patients did not present for Bayley testing. The Bayley scores were not worse in the patients who received SDINDO, despite the intervention group being born at a younger gestational age and being sicker.

Although we chose a period (2007-2014) in which there were no major changes to our institutional clinical protocols, we recognize that subtle changes in ventilator management, timing of surfactant delivery, attention to hemodynamics, and nutritional changes may have occurred during this time. However, both groups were similarly exposed to these advances over the duration of the study.

It is unlikely that further large, multi-center randomized studies of prophylactic indomethacin will be conducted [51], even though the last large multi-center study was published in 2001. Since that time, neonatologists have increasingly provided life-sustaining intensive care to infants born at 22-23 weeks who are at highest risk for severe IVH and PDA. Therapies such as prophylactic indomethacin, which some have appropriately abandoned in the more mature infants with a higher rate of spontaneous closure of the PDA [52] and lower rates of IVH, 
may be appropriate for this highly immature population $[1,7,8,14]$.

Our protocol calls for SD-INDO at $12 \mathrm{~h}$ but others have administered multi-dose indomethacin beginning at $6 \mathrm{~h}$ $[8,9,53]$. Since no adverse renal effects were shown from administration of SD-INDO at $12 \mathrm{~h}$, earlier administration of a single dose of indomethacin may maximize potential benefits, whether from improved hemodynamic stability or to a shift in the inflammatory response cascade. Future studies may evaluate whether there is increased benefit conferred if SD-INDO is given shortly after birth, as the hemodynamic instability that potentially contributes to IVH may occur well before $12 \mathrm{~h}$ of age.

In summary, a single dose of indomethacin at $12 \mathrm{~h}$ of age is associated with short- and long-term benefits in very premature infants. Given the recent trend away from prophylactic indomethacin use [54] and emerging reports of increased morbidity and mortality among infants who fail to spontaneously close the ductus arteriosus [55-62], neonatologists may consider using a single-dose prophylactic regimen to gain the benefits of ductus closure with limited drug exposure. Prospective studies are needed to determine the optimal timing and broad applicability of this approach, perhaps combined with early targeted cardiac ultrasound $[11,63,64]$.

Funding Vanderbilt Institute for Clinical and Translational Research grant support (UL1 TR000445 from NCATS/NIH) (MGK) and National Institutes of Health HL109199 and HL128386 (JR).

Author contributions MGK designed the study, performed the data collection, and wrote and revised the manuscript. RBC designed the study. CS performed statistical analysis. BR performed data collection. JR designed the study and revised the manuscript. NM designed the study, performed the data collection and performed statistical analysis.

\section{Compliance with ethical standards}

Conflict of interest The authors declare that they have no conflict of interest.

Ethics The authors affirm that research was conducted in accordance with the ethical standards of all applicable national and institutional committees and the World Medical Association's Helsinki Declaration.

Publisher's note Springer Nature remains neutral with regard to jurisdictional claims in published maps and institutional affiliations.

\section{References}

1. Dani C, Mosca F, Cresi F, Lago P, Lista G, Laforgia N, et al. Patent ductus arteriosus in preterm infants born at 23-24 weeks' gestation: should we pay more attention? Early Hum Dev. 2019;135:16-22.

2. Cotton RB, Stahlman MT, Kovar I, Catterton WZ. Medical management of small preterm infants with symptomatic patent ductus arteriosus. J Pediatr. 1978;92:467-73.
3. Schmidt B, Davis P, Moddemann D, Ohlsson A, Roberts RS, Saigal S, et al. Long-term effects of indomethacin prophylaxis in extremely-low-birth-weight infants. N. Engl J Med. 2001;344: 1966-72.

4. Koch J, Hensley G, Roy L, Brown S, Ramaciotti C, Rosenfeld $\mathrm{CR}$. Prevalence of spontaneous closure of the ductus arteriosus in neonates at a birth weight of 1000 grams or less. Pediatrics 2006;117:1113-21.

5. Nemerofsky SL, Parravicini E, Bateman D, Kleinman C, Polin $\mathrm{RA}$, Lorenz JM. The ductus arteriosus rarely requires treatment in infants > 1000 grams. Am J Perinatol. 2008;25:661-6.

6. Clyman RI, Couto J, Murphy GM. Patent ductus arteriosus: are current neonatal treatment options better or worse than no treatment at all? Semin Perinatol. 2012;36:123-9.

7. Liebowitz M, Clyman RI. Prophylactic indomethacin compared with delayed conservative management of the patent ductus arteriosus in extremely preterm infants: effects on neonatal outcomes. J Pediatr. 2017;187:119-126 e1.

8. Yoshimoto S, Sakai H, Ueda M, Yoshikata M, Mizobuchi M, Nakao H. Prophylactic indomethacin in extremely premature infants between 23 and 24 weeks gestation. Pediatr Int. 2010;52: 374-7.

9. Bandstra ES, Montalvo BM, Goldberg RN, Pacheco I, Ferrer PL, Flynn J, et al. Prophylactic indomethacin for prevention of intraventricular hemorrhage in premature infants. Pediatrics. 1988;82: $533-42$.

10. Ment LR, Oh W, Ehrenkranz RA, Philip AG, Vohr B, Allan W, et al. Low-dose indomethacin and prevention of intraventricular hemorrhage: a multicenter randomized trial. Pediatrics. 1994;93: 543-50.

11. Kluckow M, Jeffery M, Gill A, Evans N. A randomised placebocontrolled trial of early treatment of the patent ductus arteriosus. Arch Dis Child Fetal Neonatal Ed. 2014;99:F99-F104.

12. Yanowitz TD, Baker RW, Sobchak Brozanski B. Prophylactic indomethacin reduces grades III and IV intraventricular hemorrhages when compared to early indomethacin treatment of a patent ductus arteriosus. J Perinatol. 2003;23:317-22.

13. Liebowitz M, Koo J, Wickremasinghe A, Allen IE, Clyman RI. Effects of prophylactic indomethacin on vasopressor-dependent hypotension in extremely preterm infants. J Pediatr. 2017;182: $21-27$ e2.

14. Gillam-Krakauer M, Hagadorn JI, Reese J. Pharmacological closure of the patent ductus arteriosus: when treatment still makes sense. J Perinatol. 2019;39:1439-41.

15. Bhat R, Zayek M, Maertens P, Eyal F. A single-dose indomethacin prophylaxis for reducing perinatal brain injury in extremely low birth weight infants: a non-inferiority analysis. J Perinatol. 2019;39:1462-71.

16. Bada HS, Green RS, Pourcyrous M, Leffler CW, Korones SB, Magill HL, et al. Indomethacin reduces the risks of severe intraventricular hemorrhage. J Pediatr. 1989;115:631-7.

17. Ment LR, Duncan CC, Ehrenkranz RA, Kleinman CS, Pitt BR, Taylor KJ, et al. Randomized indomethacin trial for prevention of intraventricular hemorrhage in very low birth weight infants. J Pediatr. 1985;107:937-43.

18. Ment LR, Duncan CC, Ehrenkranz RA, Kleinman CS, Taylor KJ, Scott DT, et al. Randomized low-dose indomethacin trial for prevention of intraventricular hemorrhage in very low birth weight neonates. J Pediatr. 1988;112:948-55.

19. Laptook AR, O'Shea TM, Shankaran S, Bhaskar B, Network NN. Adverse neurodevelopmental outcomes among extremely low birth weight infants with a normal head ultrasound: prevalence and antecedents. Pediatrics. 2005;115:673-80.

20. Wood NS, Costeloe K, Gibson AT, Hennessy EM, Marlow N, Wilkinson AR, et al. The EPICure study: associations and antecedents of neurological and developmental disability at 30 months 
of age following extremely preterm birth. Arch Dis Child Fetal Neonatal Ed. 2005;90:F134-40.

21. Ment LR, Vohr B, Allan W, Westerveld M, Sparrow SS, Schneider $\mathrm{KC}$, et al. Outcome of children in the indomethacin intraventricular hemorrhage prevention trial. Pediatrics. 2000;105:485-91.

22. Williams J, Lee KJ, Anderson PJ. Prevalence of motor-skill impairment in preterm children who do not develop cerebral palsy: a systematic review. Dev Med Child Neurol. 2010;52:232-7.

23. Krueger E, Mellander M, Bratton D, Cotton R. Prevention of symptomatic patent ductus arteriosus with a single dose of indomethacin. J Pediatr. 1987;111:749-54.

24. Papile LA, Munsick-Bruno G, Schaefer A. Relationship of cerebral intraventricular hemorrhage and early childhood neurologic handicaps. J Pediatr. 1983;103:273-7.

25. Gordon PV. Understanding intestinal vulnerability to perforation in the extremely low birth weight infant. Pediatr Res. 2009;65:138-44.

26. Lin PW, Stoll BJ. Necrotising enterocolitis. Lancet. 2006;368: 1271-83.

27. Selewski DT, Charlton JR, Jetton JG, Guillet R, Mhanna MJ, Askenazi DJ, et al. Neonatal acute kidney injury. Pediatrics. 2015;136:e463-73.

28. Parry G, Tucker J, Tarnow-Mordi W, Group UKNSSC. CRIB II: an update of the clinical risk index for babies score. Lancet. 2003;361:1789-91.

29. Richardson DK, Corcoran JD, Escobar GJ, Lee SK. SNAP-II and SNAPPE-II: simplified newborn illness severity and mortality risk scores. J Pediatr. 2001;138:92-100.

30. Albers CA, Grieve AJ. Review of Bayley Scales of infant and toddler development - third edition. J Psychoed Assoc. 2007; 25:180-90.

31. Kuban KC, Allred EN, O'Shea M, Paneth N, Pagano M, Leviton A, et al. An algorithm for identifying and classifying cerebral palsy in young children. J Pediatr. 2008;153:466-72.

32. Palisano RJ, Rosenbaum P, Bartlett D, Livingston MH. Content validity of the expanded and revised Gross Motor Function Classification System. Dev Med Child Neurol. 2008;50:744-50.

33. McCullagh P. Regression models for ordinal data. J R Stat Soc Ser B. 1980;42:109-42.

34. Gamaleldin I, Harding D, Siassakos D, Draycott T, Odd D. Significant intraventricular hemorrhage is more likely in very preterm infants born by vaginal delivery: a multi-centre retrospective cohort study. J Matern Fetal Neonatal Med. 2019;32:477-82.

35. Humberg A, Hartel C, Paul P, Hanke K, Bossung V, Hartz A, et al. Delivery mode and intraventricular hemorrhage risk in very-low-birth-weight infants: observational data of the German Neonatal Network. Eur J Obstet Gynecol Reprod Biol. 2017; 212:144-9.

36. Shankaran S, Lin A, Maller-Kesselman J, Zhang H, O'Shea TM, Bada HS, et al. Maternal race, demography, and health care disparities impact risk for intraventricular hemorrhage in preterm neonates. J Pediatr. 2014;164:1005-1011 e3.

37. Rosenbaum P, Rubin D. The central role of the propensity score in observational studies for causal effects. Biometrika. 1983;70:41-55.

38. Gelfond JA, Heitman E, Pollock BH, Klugman CM. Principles for the ethical analysis of clinical and translational research. Stat Med. 2011;30:2785-92.

39. Thalji AA, Carr I, Yeh TF, Raval D, Luken JA, Pildes RS. Pharmacokinetics of intravenously administered indomethacin in premature infants. J Pediatr. 1980;97:995-1000.

40. Yaffe SJ, Friedman WF, Rogers D, Lang P, Ragni M, Saccar C. The disposition of indomethacin in preterm babies. J Pediatr. 1980;97:1001-6.

41. Alpert BS, Lewins MJ, Rowland DW, Grant MJ, Olley PM, Soldin SJ, et al. Plasma indomethacin levels in preterm newborn infants with symptomatic patent ductus arteriosus-clinical and echocardiographic assessments of response. J Pediatr. 1979;95: 578-82.

42. Brash AR, Hickey DE, Graham TP, Stahlman MT, Oates JA, Cotton RB. Pharmacokinetics of indomethacin in the neonate. Relation of plasma indomethacin levels to response of the ductus arteriosus. N. Engl J Med. 1981;305:67-72.

43. Wiest DB, Pinson JB, Gal PS, Brundage RC, Schall S, Ransom $\mathrm{JL}$, et al. Population pharmacokinetics of intravenous indomethacin in neonates with symptomatic patent ductus arteriosus. Clin Pharm Ther. 1991;49:550-7.

44. Vert P, Bianchetti G, Marchal F, Monin P, Morselli PL. Effectiveness and pharmacokinetics of indomethacin in premature newborns with patent ductus arteriosus. Eur J Clin Pharm. 1980; 18:83-8.

45. Ment LR, Vohr BR, Makuch RW, Westerveld M, Katz KH, Schneider KC, et al. Prevention of intraventricular hemorrhage by indomethacin in male preterm infants. J Pediatr. 2004;145:832-4.

46. Schmidt B, Roberts RS, Anderson PJ, Asztalos EV, Costantini L, Davis PG, et al. Academic performance, motor function, and behavior 11 years after neonatal caffeine citrate therapy for apnea of prematurity: an 11-year follow-up of the CAP randomized clinical trial. JAMA Pediatrics. 2017;171:564-72.

47. Spittle AJ, Cheong J, Doyle LW, Roberts G, Lee KJ, Lim J, et al. Neonatal white matter abnormality predicts childhood motor impairment in very preterm children. Dev Med Child Neurol. 2011;53:1000-6.

48. Miller SP, Mayer EE, Clyman RI, Glidden DV, Hamrick SE, Barkovich AJ. Prolonged indomethacin exposure is associated with decreased white matter injury detected with magnetic resonance imaging in premature newborns at 24 to 28 weeks' gestation at birth. Pediatrics 2006;117:1626-31.

49. Norton ME, Merrill J, Cooper BA, Kuller JA, Clyman RI. Neonatal complications after the administration of indomethacin for preterm labor. N. Engl J Med. 1993;329:1602-7.

50. Watson A, Saville B, Lu Z, Walsh W. It is not the ride: inter-hospital transport is not an independent risk factor for intraventricular hemorrhage among very low birth weight infants. J Perinatol. 2013;33:366-70.

51. Jensen EA, Dysart KC, Gantz MG, Carper B, Higgins RD, Keszler M, et al. Association between use of prophylactic indomethacin and the risk for bronchopulmonary dysplasia in extremely preterm infants. J Pediatr. 2017;186:34-40 e2.

52. Semberova J, Sirc J, Miletin J, Kucera J, Berka I, Sebkova S, et al. Spontaneous closure of patent ductus arteriosus in infants $</=1500$ g. Pediatrics. 2017;140:e20164258.

53. Mirza H, Laptook AR, Oh W, Vohr BR, Stoll BJ, Kandefer S, et al. Effects of indomethacin prophylaxis timing on intraventricular haemorrhage and patent ductus arteriosus in extremely low birth weight infants. Arch Dis Child Fetal Neonatal Ed. 2016;101: F418-22.

54. Clyman RI, Chorne N. Patent ductus arteriosus: evidence for and against treatment. J Pediatr. 2007;150:216-9.

55. Noori S, Seri I. Hemodynamic antecedents of peri/intraventricular hemorrhage in very preterm neonates. Semin Fetal Neonatal Med. 2015;20:232-7.

56. Brooks JM, Travadi JN, Patole SK, Doherty DA, Simmer K. Is surgical ligation of patent ductus arteriosus necessary? The Western Australian experience of conservative management. Arch Dis Child Fetal Neonatal Ed. 2005;90:F235-9.

57. Kaempf JW, Wu YX, Kaempf AJ, Kaempf AM, Wang L, Grunkemeier G. What happens when the patent ductus arteriosus is treated less aggressively in very low birth weight infants? J Perinatol. 2012;32:344-8.

58. Hagadorn JI, Bennett MV, Brownell EA, Payton KSE, Benitz WE, Lee HC. Covariation of neonatal intensive care unit-level patent 
ductus arteriosus management and in-neonatal intensive care unit outcomes following preterm birth. J Pediatr. 2018;203:225-233 e1.

59. Hagadorn JI, Brownell EA, Trzaski JM, Johnson KR, Lainwala S, Campbell BT, et al. Trends and variation in management and outcomes of very low-birth-weight infants with patent ductus arteriosus. Pediatr Res. 2016;80:785-92.

60. Jensen EA, Foglia EE, Schmidt B. Association between prophylactic indomethacin and death or bronchopulmonary dysplasia: a systematic review and meta-analysis of observational studies. Semin Perinatol. 2018;42:228-34.

61. Kaempf J, Huston R, Wu YX, Kaempf AJ, Wang L, Grunkemeier $\mathrm{G}$, et al. Permissive tolerance of the patent ductus arteriosus may increase the risk of chronic lung disease. Res Rep Neonatol. 2013;3:5-10.

62. Sadeck LS, Leone CR, Procianoy RS, Guinsburg R, Marba ST, Martinez FE, et al. Effects of therapeutic approach on the neonatal evolution of very low birth weight infants with patent ductus arteriosus. J Pediatr. 2014;90:616-23.

63. Farooqui MA, Elsayed YN, Jeyaraman MM, Dingwall O, Tagin M, Zarychanski R, et al. Pre-symptomatic targeted treatment of patent ductus arteriosus in preterm newborns: a systematic review and meta-analysis. J Neonatal Perinat Med. 2019;12:1-7.

64. Jetton JG, Askenazi DJ. Update on acute kidney injury in the neonate. Curr Opin Pediatr. 2012;24:191-6. 